\title{
Methylester-Artefakte in den mit Methanol extrahierten Lipiden der Frauenmilch
}

\author{
Von G. Czeglédi-Jankó \\ Aus dem Institut für Ernäbrungswissenschaft, Budapest, Ungarn (Direktor: Prof. Dr. R. Tarjän)
}

(Der Schriftleitung zugegangen am 22. Juli 1964)

\begin{abstract}
Wenn aus Frauenmilchproben, die freie Fettsäuren enthalten, nach mehrstündigem Stehen die Lipide mit Methanol extrahiert werden, entstehen in gewissen Fällen Methylesterartefakte. Solchen Milchproben vor der methanolischen Extraktion zugesetzte freie Fettsäuren werden größtenteils auch in Methylester umgewandelt. Bei Frauenmilchproben, bei denen diese Erscheinung nicht beobachtet werden kann, werden im Laufe der methanolischen Extraktion auch die zugesetzten Fettsäuren nicht in Methylester umgewandelt.
\end{abstract}

If human milk samples, which contain free fatty acids, are allowed to stand and are then extracted with methanol, methyl ester artefacts are formed in some cases. Free fatty acids, added to such samples before the methanolic extraction, are also largely converted to methyl esters. In those human milk samples, in which this esterification is not observed, added free fatty acids are also not esterified during methanolic extraction.

Extrahiert man mittels einer Chloroform-MethanolMischung $(1,2)$ die Lipide aus einer mehrere Stunden aufbewahrten - auch freie Fettsäuren enthaltenden Frauenmilch und trennt den Lipidauszug auf einer Merckschen „Silikagel G“-Dünnschicht mit einer Mischung von $60 \mathrm{~m} l n$-Heptan, $20 \mathrm{ml}$ Petroläther (Kp. $\left.40-60^{\circ}\right), 20 \mathrm{~m} l$ Diäthyläther und $1 \mathrm{~m} l$ Eisessig, so erscheint in einzelnen Fällen zwischen dem Fleck der Cholesterinester und der Triglyzeride ein neuer Fleck (Abb. 1. I.). Extrahiert man mit einem ÄthanolÄther-Gemisch $(3,4)$, tritt der Fleck nie in Erscheinung (Abb. 1. II.). Bei frischer Frauenmilch, in der freie Fettsäuren nur in verschwindend kleinen Mengen vorhanden sind, ist selbst bei methanolischer Extraktion der Fleck auf dem Chromatogramm nicht sichtbar (Äbb. 1. VII.). Da der $R_{\mathbf{F}}$-Wert des erwähnten neuen Flecks mit dem der fettsauren Methylester identisch ist (Abb. 1. III.) und der Fleck nur bei abgestandener Milch und nur in vereinzelten Fällen in Erscheinung tritt, ist es anzunehmen, daß es sich hier um fettsaure Metbylester-Artefakte handelt.

Artefakte in methanolischen Lipidextrakten wurden schon früher beschrieben $(5,6)$. JÁKY und Mitarbeiter (7) beobachteten sie in gewissen menschlichen Blutserumextrakten und brachten die Erscheinung sowie die Intensität der Flecke mit dem Gesundheitszustand des Individuums in Verbindung. Dieselben Beobachtungen wurden auch im Laufe von Verblutungsversuchen an Hasen gemacht (8). - Das Erscheinen von Artefakten auf dem Dünnschichtchromatogramm von Frauenmilchlipiden scheint nicht gesetzmäßig zu sein. Bei gesunden Müttern im Alter von $19-23$ Jahren konnte nach Extraktion mit Methanol in 16 von 25 Milchlipidextrakten die Anwesenheit von Methylester-Artefakten nachgewiesen werden.

Auf Grund der Annahme, daß die Bildung von Methylester-Artefakten hauptsächlich auf die freien Fettsäuren zurückzuführen sei, wurde, dem voraussichtlichen Gesamtlipidgehalt entsprechend, den Frauenmilchproben vor der Extraktion mit methanolischen Lösungsmittelgemischen, eine Mischung von Palmitin-,

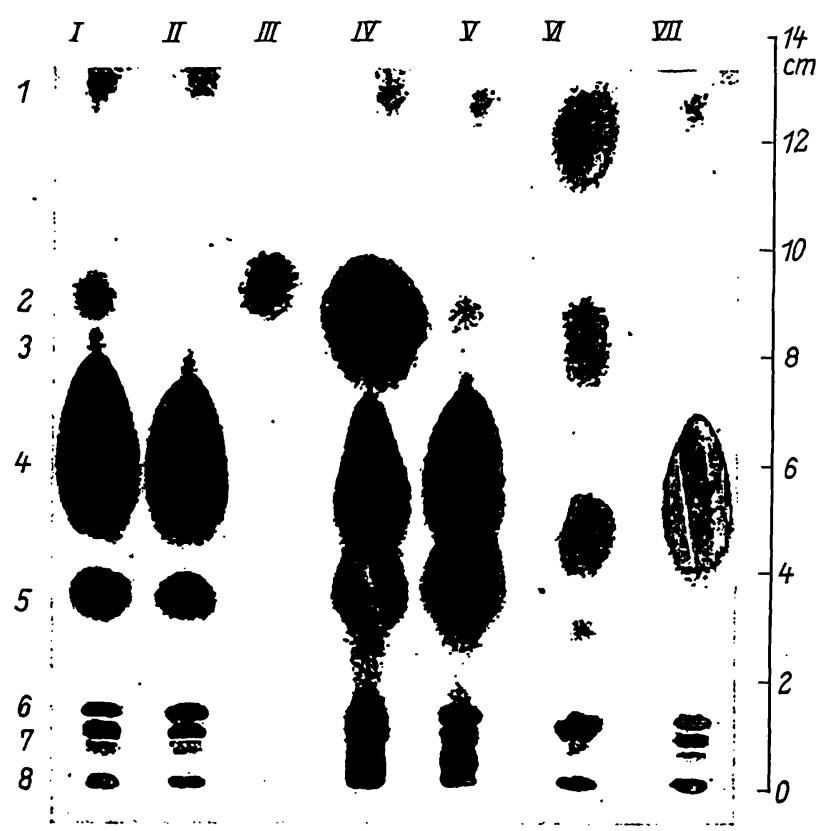

Abb. 1. Dünnschichtchromatogramme von Lipidextrakten

I. Methylester-Artefakte enthaltender Chloroform-MethanolExtrakt einer abgestandenen Frauenmilchprobe.

II. Dasselbe wie I. Die Extraktion erfolgte mit einem ÄthanolÅthyläther-Gemisch.

III. Synthetischer Fettsäure-Methylester.

IV. Dasselbe wie I. Der Probe wurde vor der Extraktion eine Fettsäure-Mischung zugesetzt.

V. Extrakt einer Artefakte nicht gebenden Frauenmilchprobe. Vor der Extraktion wurde eine Fettsäure-Mischung zugesetzt.

VI. Mit einem Chloroform-Methanol-Gemisch extrahierte und Methylester-Artefakte enthaltende menschliche Blutserumprobe (im Text nicht erwähnt), JákY's Beobachtung.

VII. Chloroform-Methanol-Extrakt einer frischen Frauenmilchprobe

1. Cholesterinester

2. Fettsäure-Methylester (Artefakte inbegriffen)

3. Glyzerinätherdiester

4. Triglyzeride

5. Freie Fettsäuren

6. Cholesterin

7. Di- und Monoglyzeride

8. Phospholipide 
Stearin-, Öl- und Linolsäure $(1: 1: 1: 1)$ zugesetzt. Bei Milchproben, die den Methylesterfleck schon ursprünglich zeigten, vergrößerte sich dieser Fleck sehr stark, während der der freien Fettsäuren nur in geringerem $\mathrm{Maße}$ verstärkt wurde (Abb. 1. IV.). Bei Milchproben hingegen, deren methanolische Lipidextrakte keinen Methylesterfleck aufwiesen, entwickelten sich auch nach Zusatz von Fettsäuren keine Methylesterflecke, oder es zeigten sich nur ganz geringe, kaum sichtbare Flecke. Demgegenüber vergrößerte sich auf dem Chromatogramm der Fleck der schon zu Beginn anwesenden freien Fettsäuren in beträchtlichem $\mathrm{Maße}$ (Abb. 1. V.). Hieraus entspringt die Vermutung, da $B$ in gewissen Fällen ein Faktor in der Frauenmilch gegenwärtig sei, der die Methylestersynthese aus den freien Fettsäuren fördert.
Die Fettsäurezusammensetzung der von der Schicht eluierten Artefekte wurde direkt gaschromatographisch bis $\mathrm{C}_{18}$ untersucht. (Gerät: Ärogtaph A-90-P; Kolonne: $10 \mathrm{FuB},{ }_{1}^{1} \mathrm{~A}^{1 "}$; Füllung: Chromosorb W 60-80 mesh, 15\% DEGS; Trägergas: $\mathrm{H}_{2}, 60 \mathrm{~m} /$ /Min.; Heiqstrom: $200 \mathrm{~mA}$; Temperatur: Kolonne $180^{\circ}$, Detektor $240^{\circ}$, Injektor $220^{\circ}$, Kollektor $215^{\circ}$ ).

Wie zu erwarten war, erschienen die Spitzen des Diagramms den Retentionszeiten der fettsauren Methylester entsprechend. In der Tabelle 1 ist auf Grund der "peak-area" der gaschromatographischen Fraktogramme das Verhältnis der Methylester der freien Fettsäuren in den ohne Methanol extrahierten Lipiden sowie der mit dem Methanolverfahren aus den Lipiden entstandenen Methylester-Artefakte einer repräsentativen Frauenmilchprobe dargestellt.

Tab. 1

\begin{tabular}{|c|c|c|c|c|c|c|c|c|}
\hline & \multicolumn{8}{|c|}{ Methylester \% } \\
\hline & $\mathrm{C}_{10}$ & $\mathrm{C}_{12}$ & $\mathrm{C}_{\mathbf{1 4}}$ & $\mathrm{C}_{16}$ & $\mathrm{C}_{18} *$ & $\mathrm{C}_{18}$ & $\mathrm{C}_{18}{ }^{*}$ & $\mathrm{C}_{18} * *$ \\
\hline Methylester der freien Fettsäuren im Frauenmilchlipid & 7,2 & 3,9 & 2,4 & 8,2 & 1,0 & 9,5 & 40,2 & 27,6 \\
\hline Methylester-Artefakte im Frauenmilchlipid & 3,6 & 6,8 & 2,8 & 14,6 & 2,0 & 14,0 & 35,8 & 20,4 \\
\hline
\end{tabular}

* einfach ungesättigt

** doppelt ungesättigt

\title{
Literatur
}

1. Folch, J., I. Ascoli, M. Lees, J. A. Meath und F. N. Le Baron, J. biol. Chemistry 191, 833 (1951). - 2. Zöllner, N. und G. Wolfram, Klin. Wschr. 40, 1098 (1962). - 3. Bloor, W. R., J. biol. Chemistry, 77, 53 (1928). - 4. Kaufmann, H. P. und H. Garlofr, Fette, Seifen, einschließl. Anstrichmittel 62, 679 (1960). - 5. Pfeifer, J. J., Mikrochim. Acta 529 (1962). -
6. Mangold, H. K., Aliphatische Lipide in E. Stahl: Dünnschichtchromatographie, S. 158. Springer-Verlag, Berlin-GöttingenHeidelberg (1962). - 7. JákY, M., A. KoRÁNYI und P. HágonY, Növényolaj Kutató Int. Közl.S. 1., Budapest, Ungarisch (1962). 8. Medgyessy, G., persönliche Mitteilung.

Dr. G. Czeglédi-Jankó Institut für Ernährungswissenschảft Budapest IX., Gyáli ut 3/a

\section{Zur quantitativen Bestimmung von Indican in Urin und Serum}

\author{
Von D. Müring und H. J. Burgard
}

Aus der 1. Medizinischen Klinik der Universität des Saarlandes, Homburg/Saar (Direktor: Prof. Dr. med. F. Doenecke)

(Der Schriftleitung zugegangen am 14. Mai 1964)

\begin{abstract}
Auf dem Prinzip der Farbreaktion nach Jolles wurde eine Methode zur Bestimmung von Indican in Urin und Serum entwickelt, deren einfache Ausführung, deren Genauigkeit und Empfindlichkeit bei geringen Mengen an Untersuchungsmaterial eine Anwendung für klinische $Z$ wecke ermöglichen.

A method was developed for the determination of indican in urine and serum, based on the colour reaction of Jolles. Its simplicity of operation, accuracy and sensitivity with small amounts of experimental material make it suitable for clinical purposes.
\end{abstract}

Die bisher bekannten Methoden der Bestimmung von Harnindican (Schwefelsäure-mono-[indolyl-(3)-ester] = Indoxylschwefelsäure) für klinische Zwecke waren entweder zu ungenau und unempfindlich oder zu schwierig und zeitraubend, als daß sie sich in der Klinik durchgesetzt hätten. Die hier angestellten Untersuchungen gehen auf die Feststellung von Jolles (1) zurück, der Indoxyl und Thymol zu einem Farbkomplex oxydierte.
Dieser besteht nach seinen Untersuchungen mit großer Wahrscheinlichkeit aus [ $p$-Cymol-(2)]-[indol-(2)]-indolignon. Von den verschiedenen Modifikationen dieser Methode bringt diejenige von RAPPAPORT und ENGELBERG (2) einen neuen Gesichtspunkt: Es bildet sich bei Verwendung von Trichloressigsäure als Eiweißfällungsmittel ein Tropfen „Öl“, in dem die Farbe löslich ist. Dieses Verhalten wurde in der Methode von 